\title{
Encouraging managers of care homes for older adults to participate in research
}

\begin{tabular}{|r|l|}
\hline Journal: & Quality in Ageing and Older Adults \\
\hline Manuscript ID & QAOA-04-2019-0017.R3 \\
\hline Manuscript Type: & Research Paper \\
\hline Keywords: & $\begin{array}{l}\text { care home managers, research recruitment, partnership working, } \\
\text { incentives, quality of life, care homes }\end{array}$ \\
\hline \multicolumn{2}{|l}{} \\
\hline
\end{tabular}

\section{SCHOLARONE \\ Manuscripts}




\begin{abstract}
Purpose: Research in care homes requires the co-operation of care home managers. Noting the challenges faced by the care home sector, this article considers ways in which research studies can encourage care home managers and their homes to participate in research.
\end{abstract}

Approach: The discussion is informed by two research projects which are used to explore methods of encouraging managers of care homes to participate in research. One of the studies included interviews with care home managers to understand their reasons for taking part in research.

Findings: This paper outlines and assesses three strategies for encouraging care home managers to participate in research; working in partnership, providing payment and providing personalised feedback on findings. While all the strategies have the potential to encourage care home managers' participation in research, partnership working in particular was found to be fraught with difficulties. Research implications: This paper suggests the research projects could employ any of these strategies to encourage managers of care homes to participate in research. It also suggests that proactive measures could help ameliorate the pitfalls of partnership working.

Originality: This paper shows the advantages and disadvantages to using a combination of strategies for encouraging the participation of care home managers in research.

The authors would like to thank all the residents, family members, staff and homes who took part in this research and the local authorities who supported it.

\title{
Introduction
}

Across health and social care, recruitment to research can be problematic (Bower et al., 2009; Patel et al., 2003) particularly among older people (Clegg et al., 2015; MacFarlane et al., 2016; McMurdo et al., 2011) for whom barriers to participating in research include poor health, tiredness and lack of support from family members (Liljas et al., 2017). However, this issue is rarely reported (Gul and Ali, 2010) and evidence around ways to improve it is sparse (Bower et al., 2009). 
Around 425,000 adults aged over 65 live in care homes in England (Buisson, 2014). Care homes in England operate in quasi-market (Barron and West, 2017) and provide accommodation alongside care and support. While this has traditionally focused on supporting personal care, keeping people safe and fed, many aim to help their residents engage in activities and social interaction. In some homes, refered to a nursing home, nursing support is also provided. Research in these care settings brings additional challenges (Ellwood et al., 2018) as it requires the co-operation of care staff (Goodman et al., 2011). Key to success is engaging the care home manager. However, care home managers face a set of challenges, which may mean that research is not a priority and finding time to participate in research is difficult (Davies et al., 2014). At the forefront of these challenges are financial issues. While many local authorities (LAs) have tried to protect social care, consistent budget cuts have had an impact (Bolton, 2016; Innes and Tetlow, 2015; Local Government Association, 2014). Care homes have also experienced a rise in costs (Laing and Buisson, 2014), not least through implementing the National Living Wage (Ingham et al., 2015) but also due to difficulties recruiting and retaining skilled staff (Burtney et al., 2014; Rubery et al., 2011) and increased use of agency or temporary staff (Registered Nursing Home Association, 2014). Meeting residents' needs in the face of these financial pressures, whilst balancing the regulatory requirements of national regulator for health and social care, the Care Quality Commission (CQC), and the contractual requirements of local commissioners means that many managers may hesitate before adding to their workloads by engaging in research.

Despite this difficult context, a new incentive for care home managers to participate in research emerged at the end of 2014 with changes in the way social care is regulated in England. The CQC, reconfigured its approach and moved from a system that referenced minimum standard to one that applies four quality ratings; inadequate, requires improvement, good, and outstanding. CQC now explicitly encourage social care providers to participate in research by stating that services rated as outstanding should "strive for excellence through consultation, research and reflective practice" (Care Quality Commission, 2017, p. 69).

It is in the above context that the two studies that we draw on for this article were undertaken. Both studies, the ASCOT Feedback Intervention Study (AFIS) and Measuring Outcomes of Care Homes $(\mathrm{MOOCH})$, collected data from care homes in the South East of England. A number of recruitment strategies were put in place, in line with best practice (ENRICH, 2019; Luff et al., 2011) with varying success.

Neither of these studies explicitly aimed to explore how to encourage care homes to engage in care home research. Instead, both studies were focused around the measurement of residents' quality of 
life. Fuller discussion of these projects and their findings can be found in anonymous (2016) and anonymous (2019). This paper presents retrospective reflections on three strategies employed across the two projects to help engage care home managers in our research and aid recruitment of homes to the study. It also draws on a small piece of research, carried out as part of the second study, that asked care home managers about their experience of and motivation for participating in research.

\section{Study one: ASCOT Feedback Intervention Study (AFIS; 2012-14)}

AFIS built on conversations with care practitioners about the impact of collecting outcomes data on care practice. It aimed to pilot a feedback intervention and examine both its acceptability and any changes in staff practice and/or quality of life experienced by residents after feedback had been delivered. From the early design stage we partnered a single national care home organisation whose homes were listed as being 'research ready' on the NIHR Enabling Research in Care Homes (ENRICH) website (ENRICH, 2019). Representatives from this organisation also participated in the study's advisory group. AFIS was initially designed as a comparison of four experimental and four control homes with two data collections periods, spaced three months apart. At each time point, two researchers would spend up to two weeks in each home collecting data using the care home version of the Adult Social Care Outcomes Toolkit (ASCOT) (Netten, Burge, et al., 2012; Netten, Trukeschitz, et al., 2012; Smith, Towers, \& Razik, 2017). In the experimental group, feedback sessions about our findings would be held with staff shortly after the first data collection point. However, the study quickly experienced difficulties in engaging home managers. While senior management at the organisation's regional and national level had been enthusiastic, information about the study was rarely passed to individual home managers. This was exacerbated by high levels of turnover amongst the organisation's senior management team. In response to these ongoing issues the study design was revised and explored the feasibility and acceptability of the feedback intervention (Anonymous, 2016). The final study included six homes and 72 residents. Two of the homes participating in the feasibility study came from the original partner organisation and the other two were recruited from a small independent provider (Laing and Buisson, 2012) following invitation letters being sent to care homes in the LA where we had received research governance. All homes in the study received the feedback intervention.

\section{Study two: Measuring the outcomes of care homes (MOOCH; 2015-2018)}


The MOOCH study began as partnership with a single LA quality monitoring team who wanted to extend their care home monitoring process to capture residents' quality of life. An ASCOT-based monitoring tool, identified in previous research to be of interest to monitoring teams (Towers et al., 2015), would be piloted by the quality monitoring officers. Individual level quality of life data would be collected from around 300 residents in 30 care and nursing homes using ASCOT. However, due to LA restructuring, the quality monitoring team had to withdraw from the study. The research was moved to two different LAs with a focus on exploring links between the researcher-collected ASCOT scores and the new CQC ratings. This revised study was supported by the new LAs, and in particular one LA's commissioning team, and local CQC inspectors. Representatives of both organisations were invited to join the Research Advisory Group. We also reviewed our approach to recruitment. In addition to active promotion by both the LA commissioning team and the project's advisory group members, participating homes were offered both a small participation payment ( $£ 200$, including VAT) and a personalised feedback report focusing on the impact of the home on residents' carerelated quality of life. In total, 293 residents participated in the final study with researchers spending between one and three days in each of the 34 homes. More details about the $\mathrm{MOOCH}$ study can be found in Anonymous et al. (2019)

The difficulties we had previously encountered in engaging care home managers in research prompted us to invite the managers of each home in the study to participate in a structured telephone interview. The aim of this interview was to understand their motivations for and experience of participating in the research, and to find out how they had used the small participation payment. Managers from 30 of the 34 homes participated in the interviews. Each interview was led by a researcher who had not been involved in collecting that home's data and took place after data collection and feedback. The interviews, which lasted up to twenty minutes, consisted of predominately structured questions, supplemented by open ended questions. Answers to the questions were typed directly into an electronic data entry tool. Data from the open-ended questions was analysed using NVIVO10. Thematic analysis (Braun and Clarke, 2006) was used to analyse this material and was used to help us reflect on the strategies outlined in this paper.-

\section{Similarities between the studies}

Although different in design, there were similarities between the two studies. Carried out by broadly the same research team, the two studies were aimed to measure and improve understanding of residents' quality of life. Both studies provided tailored feedback on residents' quality of life to participating homes. Both projects were supported by advisory groups comprised of relevant stakeholders, including Patient and Public Involvement (PPI) representatives and, in the 


\section{Strategies for encouraging care home managers to participate in research Working in partnership}

We also collaborated with a range of partners including large and smaller care home providers, LAs, and statutory bodies such as CQC. Representatives from these organisations, alongside public and patient involvement representatives, helped shape and guide the research, either via membership of advisory groups or, in the case of one local authority, via a long period of working collaboratively on the funding application. In both studies, working more closely in partnership with at least one other organisation mentioned above was a key strategy to improve recruitment. Partnership working across the two studies also included working together to meet the aims of the project, for example advertising the project, directly aiding recruitment and helping disseminate findings. Partnership working can have many benefits, including facilitating research relevance and improving pathways to impact. It has also been endorsed as a promising way of engaging care home managers and recruiting both homes and residents to a study. However, our experience across the two studies suggests a more complex picture where there are also a number of challenges, which can impact negatively on engaging home managers.

The first challenge our work identified was the tension between academic and care provider partners. Differing timescales was a reason for this. Academic institutions are accustomed to remarkably long times between initial research idea and publication of findings; it may be two or three years before even any data are collected. Provider organisations tend to move much faster and want results as soon as possible. These long time-scales can de-rail partnerships, as wider social, financial and political context changes impact on partners' priorities. For example, in our second study, the original research was shaped by the needs of the LA quality monitoring team. However, during the two year period between planning and beginning data collection, LA priorities changed and the monitoring team who partnered and supported the study were disbanded. 
Timescales also had a more direct impact on building relationships and engaging with care home managers, owing to relatively high levels of staff turnover in the social care sector (Hussein et al., 2016; Rubery et al., 2011). In the AFIS study, our access to homes and their managers was to be facilitated by our partner, a large commercial care organisation. However, staff turnover at the organisation's regional level outpaced the research and before individual homes were recruited, key regional personnel had left the organisation, making engaging with homes even harder. This experience was repeated, albeit to a lesser degree, during $\mathrm{MOOCH}$, but it was also evident in individual homes with several managers leaving during the study period: one home had three different managers within a year. Even when homes have been recruited, high levels of staff turnover means that relationships with all partners have to be negotiated throughout the study, which can have a negative impact on recruitment, data collection, feedback and impact.

For partnership working to facilitate engagement and research, our studies suggest partner organisations should have good relationships with individual homes and managers. Across the two studies there have been positive examples of this.

In $\mathrm{MOOCH}$, as part of the final telephone interviews, managers were offered a list of possible reasons for participating in the study. Table 1 below shows the percentage of home managers reporting which reasons were important to their participation.

\section{Table one here}

Table 1 shows that some (37\%) care home managers saw our association with CQC, and their explicit support for the study, as a reason to take part. Fewer managers, around one in five, cited LA support as a motivation for participating, but this downplays the importance of this relationship to engaging care home managers. The LA was instrumental in helping us meet managers, by inviting us to local events organised for home managers.

Our experience from these studies suggests that partnerships alone do not necessarily guarantee that the research will (1) go smoothly or (2) be well-received by homes and managers. It is a complex picture and vital to consider timescales, the partners' internal and external relationships and the external pressures on partners - not all of these will be known, and they may also change over time. In the first study (AFIS), poor communication between the organisation's regional and national teams with individual homes meant, as others have noted (Luff et al., 2011), renegotiating consent with the home managers at several points in the study. In the second study, our association with the first LA quality monitoring team appeared to be a barrier to recruitment because of their poor relationship with local care home providers and managers. Attendance at the LA-sponsored research 
recruitment events was very low, and there were openly adversarial interactions between the LA and care providers, caused in part by planned austerity measures. Prior to the LA restructuring and consequently withdrawing from the research just one home had been recruited.

\section{Providing payment}

Both studies included 'thank you' vouchers for the residents who participated in the study. However, in the second study, $\mathrm{MOOCH}$, our strategy to engage care home managers and recruit them to the study also included a one-off payment of $£ 200$ to the home.

There is evidence to suggest that money increases individual's willingness to participate in research (Bentley and Thacker, 2004; Halpern, 2011). Payment in the form of thank you vouchers for individual research participants is now well established. It is rarely viewed as controversial despite residual concerns that such payments are a form of coercion (Macklin, 1989) or represent undue inducement; so that potential participants do not fully evaluate the risks of participation or ignore any reluctance they may have about participation (McNeil, 1997).

While paying general practitioners to help with patient recruitment has also become accepted practice (Draper et al., 2009), paying social care organisations to support recruitment is less wellestablished although on the increase in care home research (see for example Hood et al., 2014; Livingston et al., 2017) and is accepted by some research funders. The well-rehearsed ethical concerns around payments to individuals are also applicable when organisations are provided with payment in return for participating in research. Moreover, payment may create tension between the organisation's interest in the payment and their role in protecting the best interests of those they must try to recruit (Rodwin, 2004) as it acts as an undue inducement for the home to participate in research. However, we suggest that the way payment is presented to organisations, and the total amount paid can minimise this tension significantly.

A very high level of payment exceeding what it costs the care home to participate, or as Dickert and Grady (1999) term it, a 'market' model, has the greatest potential to foster undue inducement. In contrast to the 'wage/'reimbursement' or 'appreciation' models, payment under the market model exceeds what it costs the care home to participate. In the 'wage/reimbursement' model payment compensates the care home for research-related costs based on staff time or additional expenses. This approach have been used successfully in care homes research (see for example, Hood et al., 2014;) and also informs the ENRICH endorsed Department of Health Attributing the costs of health and social care research guidance (Department of Health, 2012). 
The 'wage'/reimbursement' model appear to conceptualise research as an additional duty, and therefore are most appropriate where, for example, data collection is delegated to care home staff. For the MOOCH study, care home staff were not undertaking research-related duties and so our payment strategy drew on the 'appreciation' model. Indeed, our approach to gathering data on residents' quality of life and lived experience is designed to be as unobtrusive as possible, with minimal impact on the daily routine of the care home. While having no impact is clearly not possible (Mccambridge et al., 2014), the post-fieldwork interviews with managers, suggest that having researchers in the home did not interfere with the daily life of the home:

"[the fieldworkers] were lovely - we didn't really know they were there they were so discreet! They ... didn't impact negatively at all, they just moulded in." (Independent residential home manager study two)

We also saw our payments as a way of recognising the care home's key role in the research process. Data suggest that the homes' managers did not see the transaction as purely financial either. As Table 2 shows, no managers used their payment to cover staff costs. Instead they tended to use the money to provide additional items, such as Christmas parties for residents and their families, days out for residents, or a staff party.

\section{Table two here}

Approaching payment to homes in this manner also addresses ethical concerns around undue inducement as the payment is unlikely to be high enough to increase the tension between the homes' and residents' interests. But is the payment too low to encourage participation? Table 1 suggests the $\mathrm{MOOCH}$ care home managers did not see the payments as an important factor in their participation in the study. Clearly this may reflect some social bias around admitting the influence of financial incentives on decisions and certainly the research team felt that even if the payment had no direct impact on recruitment of either homes or residents, it enhanced engagement across all the study processes.

\section{Providing personalised feedback}

Both studies went beyond just providing generic findings to participating homes and gave care home managers and staff with anonymised feedback on the quality of life of their home's participating residents. In the AFIS, the research team held several feedback sessions in each home, giving staff the opportunity to discuss findings and question the research team. In $\mathrm{MOOCH}$, feedback was 


\section{Discussion}

Managers are key to undertaking research in care homes and here we have identified three strategies from our studies which can encourage them to engage with and participate in research; working in partnership, payment to homes and providing personalised feedback.

Of these three strategies, providing personalised feedback is the one most closely linked to reasons why care home managers say they participated in our studies. It is also reflected in the work of others who have carried out care home research. Head and Lanza (2015) in an ENRICH case study on ethics in care home research suggest, in the light of their own study (Cassell et al., 2018), that researchers need to think about how they can give something back to care homes that take part in research, whereas Luff et al's. (2011) methods review of care home research highlights, among many 
other strategies, the duty of researcher to both make clear the potential benefits of the research to the care home and its residents and staff.

While providing personalised feedback is clearly a positive strategy, the approach research teams use to share findings can aid or hinder how managers and their staff use them. Our experiences suggest a didactic model is less useful than one that uses findings as a starting point for a conversation about ways of improving quality.

The second strategy to encourage engagement was giving the homes a payment for participating in the research. Very few managers reported that payment was a key driver for their participation but the payment offered was relatively small. Despite this we feel that payment is important and has a symbolic value; a recognition that researchers see care homes as an important partner in the research and do not take them for granted.

The final strategy, working in partnership, is the more complex, having both benefits and challenges. While partnership working has the potential to help engage home managers and aid recruitment, our experiences across the two studies suggest the context may generate issues that counteract these attempts. It is perhaps not surprising that, compared to the other strategies outlined, partnership is more ambiguous in outcome. Payment and providing personalised feedback are strategies where the research team has a greater level of control. They are often decided at any early stage of the research, probably when designing the study, contractually agreed, and in place for the project's duration. Partnerships, on the other hand, are subject to a greater range of forces, many outside the researcher's control. External forces, and partners' responses, are organic and evolve. This may lead to changes in personnel in key positions and priorities of partnership organisations over the project duration. Such changes cannot be forecast and given the long timescales for academic research, are likely to occur throughout a study's duration.

It may only be possible to judge the success of partnership working towards the end of a study, but are there ways in which researchers can attempt to mitigate the pitfalls and ensure that partnerships are positive? One approach may be the use of legal contracts to enforce cooperation and partnership. However, to many researchers this may feel inappropriate. Consent is a key ethical foundation for contemporary research (Flory and Emanuel, 2004; Nijhawan et al., 2013), often operationalised as informed consent (see for example Economic and Social Research Council, 2015, p. 29) 
This principle extends beyond recruitment, and demands that individuals who participate in research are free to withdraw at any time and for any reason. To us, taking a very different approach, such as contractually obliging organisations to participate would seem incongruous and unethical.

More comfortable, and indeed more fruitful, approaches draw on researchers and partnership organisations working closely together to find ways of sharing what can, at times, be very different perspectives. The real challenge is how researchers can move these broad ideas into research practice. One such method is the 'embedded researcher' who works within the partnership organisation as a staff member but who is also affiliated to an academic institution, thus moving towards co-production of the research (Cheetham et al., 2018; Vindrola-Padros et al., 2017). Similarly, partnerships and co-production might be fostered by staff within partner organisations being directly funded as part of a research project.

Another approach may be to focus on sharing perspectives within partnerships. The NIHR-funded ENRICH initiative provides resources to support different stakeholders in care home research. For example, as well guidance for the research community on undertaking research in care homes, its toolkit helps care home staff understand "what it means to support research". Many homes on the ENRICH website are flagged as being 'research ready', but, as our work has shown, helping wider research organisations (including LAs or regulatory bodies) to be 'research ready' may be key to successful partnerships.

\section{Conclusion}

Based on two research projects, this paper has outlined three strategies for encouraging care home managers and their overarching organisations to engage with research: providing personalised feedback, providing payments to homes, and partnership working. While each has the potential to encourage care home managers engagement with and participation in research, these strategies are not without their challenges. Working in partnership with other organisations to carry out research, in particular, was found to be fraught with difficulties. However, we suggest that there are proactive measures researchers can take to avoid the pitfall of partnership working, such as 'embedded researchers' and expanding the ENRICH-endorsed idea of 'research ready' beyond care homes to other organisations such as LAs. This requires time and resources on the part of both researcher and the organisation, but will also allow researchers to gain a better understand of the challenges those organisations face. A challenge for researchers, of course, is getting research funders to finance these activities. 


\section{References}

Barron, D.N. and West, E. (2017) The quasi-market for adult residential care in the UK: do for-profit, not-for-profit or public sector residential care and nursing home provide better quality care? Soc Sci Med, Vol. 197, pp137-146.

Bentley, J.P. and Thacker, P.G. (2004), "The influence of risk and monetary payment on the research participation decision making process", Journal of Medical Ethics, Vol. 30 No. 3, pp. 293-298.

Bolton, J. (2016), What Are the Opportunities and Threats for Further Savings in Adult Social Care?, Institute of Public Care, London.

Bower, P., Wallace, P., Ward, E., Graffy, J., Miller, J., Delaney, B. and Kinmonth, A.L. (2009), "Improving recruitment to health research in primary care", Family Practice, Vol. 26 No. 5, pp. 391-397.

Braun, V. and Clarke, V. (2006), "Using thematic analysis in psychology", Qualitative Research in Psychology, Vol. 3 No. 2.

Buisson, LW. (2014) Care of older people: UK Market report 26 $6^{\text {th }}$ dition, London,

Burtney, L., Figgett, D., Fullerton, D., Buchanan, P., Stevens, K. and Cooper-Ueki, M. (2014), Learning for Care Homes from Alternative Residential Care Settings, Joseph Rowntree Foundation, York.

Care Quality Commission. (2017), "Key lines of enquiry, prompts and ratings; characteristics for adult social care services", 2017, available at: http://www.cqc.org.uk/sites/default/files/20171020adult-social-care-kloes-prompts-and-characteristics-showing-changes-final.pdf (accessed 7 January 2019).

Cassell, J.A., Middleton, J., Nalabanda, A., Lanza, S., Head, M.G., Bostock, J., Hewitt, K., et al. (2018), "Scabies outbreaks in ten care homes for elderly people: a prospective study of clinical features, epidemiology, and treatment outcomes", The Lancet Infectious Diseases, Elsevier, Vol. 18 No. 8, pp. 894-902.

Cheetham, M., Wiseman, A., Khazaeli, B., Gibson, E., Gray, P., Van Der Graaf, P. and Rushmer, R. (2018), “Embedded research: a promising way to create evidence-informed impact in public health?", Journal of Public Health, Vol. 40 No. suppl_1, pp. i64-i70.

Clegg, A., Relton, C., Young, J. and Witham, M. (2015), "Improving recruitment of older people to clinical trials: use of the cohort multiple randomised controlled trial design", Age and Ageing, Vol. 44 No. 4, pp. 547-550.

Davies, S.L., Goodman, C., Manthorpe, J., Smith, A., Carrick, N. and Iliffe, S. (2014), "Enabling research in care homes: an evaluation of a national network of research ready care homes", BMC Medical Research Methodology, Vol. 14 No. 1, p. 47.

Department of Health. (2012), "Attributing the costs of health and social care research and 
development (AcoRD)", London, available at:

https://assets.publishing.service.gov.uk/government/uploads/system/uploads/attachment_dat a/file/351182/AcoRD_Guidance_for_publication_May_2012.pdf (accessed 24 November 2018).

Dickert, N. and Grady, C. (1999), "What's the price of a research subject? Approaches to payment for research participation", New England Journal of Medicine, Vol. 341 No. 3, pp. 198-203.

Draper, H., Wilson, S., Flanagan, S. and Ives, J. (2009), "Offering payments, reimbursement and incentives to patients and family doctors to encourage participation in research", Family Practice, Vol. 26 No. 3, pp. 231-238.

Economic and Social Research Council. (2015), "ESRC Framework for research ethics:: updated Janaury 2015", Swindon, available at: https://esrc.ukri.org/files/funding/guidance-forapplicants/esrc-framework-for-research-ethics-2015/ (accessed 12 December 2018).

Ellwood, A., Airlie, J., Cicero, R., Cundill, B., Ellard, D.R., Farrin, A., Godfrey, M., et al. (2018), "Recruiting care homes to a randomised controlled trial", Trials, Vol. 19 No. 1, available at:https://doi.org/10.1186/s13063-018-2915-x.

ENRICH. (2019), "A toolkit for care home research", available at: https://enrich.nihr.ac.uk/ (accessed 25 January 2019).

Flory, J. and Emanuel, E. (2004), “Interventions to improve research participants' understanding in informed consent for research", JAMA, Vol. 292 No. 13, pp. 1593-1601.

Goodman, C., Baron, N.L., Machen, I., Stevenson, E., Evans, C., Davies, S.L. and Iliffe, S. (2011), "Culture, consent, costs and care homes: Enabling older people with dementia to participate in research", Aging \& Mental Health, Vol. 15 No. 4, pp. 475-481.

Gul, R.B. and Ali, P.A. (2010), "Clinical trials: the challenge of recruitment and retention of participants", Journal of Clinical Nursing, Vol. 19, pp. 227-233.

Halpern, S.D. (2011), “Financial Incentives for Research Participation: Empirical Questions, Available Answers and the Burden of Further Proof", American Journal of the Medical Sciences, Vol. 342 No. 4, pp. 290-293.

Head, M. and Lanza, S. (2015), "Ethical concerns raised by research in care homes-getting it right Background", available at: https://enrich.nihr.ac.uk/files/Case Studies/cs-05-Ethical-ConcernsNew.pdf (accessed 13 December 2018).

Hood, K., Nuttall, J., Gillespie, D., Shepherd, V., Wood, F., Duncan, D., Stanton, H., et al. (2014), "Probiotics for Antibiotic-Associated Diarrhoea (PAAD): A prospective observational study of antibiotic-associated diarrhoea (including Clostridium difficile-associated diarrhoea) in care homes", Health Technology Assessment, Vol. 18 No. 63, available at:https://doi.org/10.3310/hta18630. 
Hussein, S., Ismail, M. and Manthorpe, J. (2016), "Changes in turnover and vacancy rates of care workers in England from 2008 to 2010: panel analysis of national workforce data", Health and Social Care in the Community, Vol. 24, pp. 547-556.

Ingham, H., Bamford, S.M. and Jones, G. (2015), The Costs and Benefits of Paying All the Lowest-Paid Care Home Workers the UK the Living Wage, Joseph Rowntree Foundation, York.

Innes, D. and Tetlow, G. (2015), "Delivering Fiscal Squeeze by Cutting Local Government Spending", Fiscal Studies, Vol. 36, pp. 303-325.

Laing, B. and Buisson. (2012), Care of Elderly People UK Market Survey 2011/12, 24th Edition, LaingBuison, London.

Laing and Buisson. (2014), Care of Older People: UK Market Report 26th Edition 2013/2014, LaingBuisson, London.

Liljas, A.E.M., Walters, K., Jovicic, A., lliffe, S., Manthorpe, J., Goodman, C. and Kharicha, K. (2017), "Strategies to improve engagement of 'hard to reach' older people in research on health promotion: a systematic review", BMC Public Health, Vol. 17, p. 349.

Livingston, G., Barber, J., Marston, L., Rapaport, P., Livingston, D., Cousins, S., Robertson, S., et al. (2017), "Prevalence of and associations with agitation in residents with dementia living in care homes: MARQUE cross-sectional study", BJPsych Open, Cambridge University Press, Vol. 3 No. 4, pp. 171-178.

Local Government Association. (2014), Under Pressure - How Councils Are Planning for Future Cuts, Local Government Association, London.

Luff, R., Ferreira, Z. and Meyer, J. (2011), Care Homes: Methods Review 8, NIHR School for Social Care Research, London.

MacFarlane, S., Charlton, K., Ferguson, A., Barlogie, J., Lynch, P., McDonell, L., Connolly, W., et al. (2016), "Difficulties in recruiting frail older inpatients to intervention studies", Nutrition \& Dietetics, Vol. 73 No. 4, pp. 348-355.

Macklin, R. (1989), "The Paradoxical Case of Payment as Benefit to Research Subjects", IRB: Ethics and Human Research, Vol. 11 No. 6, pp. 1-3.

Mccambridge, J., Witton, J. and Elbourne, D.R. (2014), "Systematic review of the Hawthorne effect : New concepts are needed to study research participation effects", Journal of Clinical Epidemiology, Elsevier Inc, Vol. 67 No. 3, pp. 267-277.

McMurdo, M.E.T., Roberts, H., Parker, S., Wyatt, N., May, H., Goodman, C., Jackson, S., et al. (2011), "Improving recruitment of older people to research through good practice", Age and Ageing, Vol. 40 No. 4, pp. 659-665.

McNeil, P. (1997), "Paying People to Participate in Research: Why not?", Bioethics, Vol. 11, pp. 390- 
396.

Netten, A., Burge, P., Malley, J., Potoglou, D., Towers, A., Brazier, J., Flynn, T., et al. (2012),

"Outcomes of social care for adults: Developing a preference-weighted measure.", Health

Technology Assessment, Vol. 16 No. 00.

Netten, A., Trukeschitz, B., Beadle-Brown, J., Forder, J., Towers, A.-M. and Welch, E. (2012), "Quality of life outcomes for residents and quality ratings of care homes: is there a relationship?", Age and Ageing, Vol. 41 No. 4, pp. 512-517.

Nijhawan, L.P., Janodia, M.D., Muddukrishna, B.S., Bhat, K.M., Bairy, K.L., Udupa, N. and Musmade, P.B. (2013), "Informed consent: Issues and challenges", J Adv Pharm Technol Res., Vol. 4 No. 3, pp. 134-140.

Patel, M.X., Doku, V. and Tennakoon, L. (2003), "Challenges in recruitment of research participants", Advances in Psychiatric Treatment, Cambridge University Press, Vol. 9 No. 3, pp. 229-238.

Registered Nursing Home Association. (2014), "Nursing - A sector in crisis", available at: http://www.rnha.co.uk/web_images/pdfs/call_for_evidence_rnha.pdf (accessed 6 December 2018).

Rodwin, M. (2004), "Financial incentives for doctors”, BMJ, Vol. 328, p. 1328.

Rubery, J., Hebson, G., Grimshaw, D., Carroll, M., Smith, L., Marchington, L. and Ugarte, S. (2011), The Recruitment and Retention of a Care Workforce for Older People, European Work and Employment Research Centre (EWERC) University of Manchester, Manchester.

Smith, N., Towers, A.-M. and Razik, K. (2017), Adult Social Care Outcomes Toolkit (ASCOT) CH3 Guidance. Version 1.0. Discussion Paper 2935., Canterbury.

Towers, A.-M., Holder, J., Smith, N., Crowther, T., Netten, A., Welch, E. and Collins, G. (2015), "Adapting the adult social care outcomes toolkit (ASCOT) for use in care home quality monitoring: conceptual development and testing", BMC Health Services Research, BioMed Central, Vol. 15 No. 1, p. 304.

Towers, A., Palmer, S., Smith, N., Collins, G. and Allen, S. (2019), “A cross-sectional study exploring the relationship between regualtor quality and care home residents' quality of life in England", Health and Quality of Life Outcomes, Vol. 17, No.22available at: https://doi.org//10.1186/s12955-019-1093-1.

Towers, A., Smith, N., Palmer, S., Welch, E. and Netten, A. (2016), "The acceptability and feasibility of using the Adult Social Care Outcomes Toolkit (ASCOT) to inform practice in care homes", BMC Health Services Research, Vol. 16 No. 1, p. 523.

Vindrola-Padros, C., Pape, T., Utley, M. and Fulop, N.J. (2017), "The role of embedded research in quality improvement: A narrative review", BMJ Quality and Safety, Vol. 26 No. 1, pp. 70-80. 
Quality in Ageing and Older Adults

Page 16 of 19

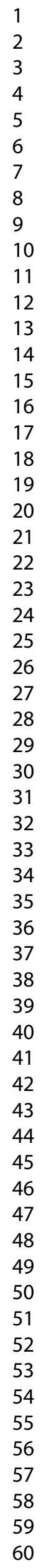

16 
Page 17 of 19

Quality in Ageing and Older Adults

$$
\begin{aligned}
& 1 \\
& 2 \\
& 3 \\
& 4 \\
& 5 \\
& 6 \\
& 7 \\
& 8 \\
& 9 \\
& 10 \\
& 11 \\
& 12 \\
& 13 \\
& 14 \\
& 15 \\
& 16 \\
& 17 \\
& 18 \\
& 19 \\
& 20 \\
& 21 \\
& 22 \\
& 23 \\
& 24 \\
& 25 \\
& 26 \\
& 27 \\
& 28 \\
& 29 \\
& 30 \\
& 31 \\
& 32 \\
& 33 \\
& 34 \\
& 35 \\
& 36 \\
& 37 \\
& 38 \\
& 39 \\
& 40 \\
& 41 \\
& 42 \\
& 43 \\
& 44 \\
& 45 \\
& 46 \\
& 47 \\
& 48 \\
& 49 \\
& 50 \\
& 51 \\
& 52 \\
& 53 \\
& 54 \\
& 55 \\
& 56 \\
& 57 \\
& 58 \\
& 59 \\
& 60
\end{aligned}
$$

17 


\section{Tables}

Table 1: Care home manager's reasons for participating in research $(n=30)$

\begin{tabular}{|l|c|c|}
\hline Reason & \multicolumn{2}{|c|}{$\begin{array}{c}\text { Managers reporting it was one of } \\
\text { reasons they took part }\end{array}$} \\
\hline & $\%$ & $\mathrm{n}$ \\
\hline Supported by Local Authority & 20 & 6 \\
\hline Supported by CQC & 37 & 11 \\
\hline Payment & 0 & 0 \\
\hline Vouchers for residents and staff & 3 & 1 \\
\hline Feedback on results & 67 & 20 \\
\hline Research looked on favourably by CQC & 27 & 8 \\
\hline Research can play a role in improving peoples' lives & 77 & 23 \\
\hline
\end{tabular}


Table 2: How managers and homes used the payment ( $n=2930$ )

\begin{tabular}{|l|c|c|}
\hline How does the care home plan to use the money? & $\mathbf{\%}$ & $\mathbf{n}$ \\
\hline Salary/overhead & 0 & 0 \\
\hline Staff experience & 7 & 2 \\
\hline Resident experience & $93 \underline{90}$ & 27 \\
\hline No response & $\underline{3}$ & $\underline{1}$ \\
\hline
\end{tabular}

